\title{
Article \\ ARLEAN: An Augmented Reality Learning Analytics Ethical Framework
}

\author{
Athanasios Christopoulos ${ }^{1, *}$, Stylianos Mystakidis ${ }^{2,3} \mathbb{D}^{\mathbb{D}}$, Nikolaos Pellas ${ }^{4}$ (D) and Mikko-Jussi Laakso ${ }^{1}$ \\ 1 Centre for Learning Analytics, Department of Computing, University of Turku, 20500 Turku, Finland; \\ milaak@utu.fi \\ 2 School of Natural Sciences, University of Patras, 26504 Rio, Greece; smyst@upatras.gr \\ 3 School of Humanities, Hellenic Open University, 26335 Patra, Greece \\ 4 Department of Primary Education, University of Western Macedonia, 53100 Florina, Greece; \\ aff00192@uowm.gr \\ * Correspondence: atchri@utu.fi
}

Citation: Christopoulos, A.; Mystakidis, S.; Pellas, N.; Laakso, M.-J. ARLEAN: An Augmented Reality Learning Analytics Ethical Framework. Computers 2021, 10, 92. https://doi.org/10.3390/ computers 10080092

Academic Editor: George

Angelos Papadopoulos

Received: 18 June 2021

Accepted: 27 July 2021

Published: 30 July 2021

Publisher's Note: MDPI stays neutral with regard to jurisdictional claims in published maps and institutional affiliations.

Copyright: (c) 2021 by the authors. Licensee MDPI, Basel, Switzerland. This article is an open access article distributed under the terms and conditions of the Creative Commons Attribution (CC BY) license (https:// creativecommons.org/licenses/by/ $4.0 /)$.

\begin{abstract}
The emergence of the Learning Analytics (LA) field contextualised the connections in various disciplines and the educational sector, acted as a steppingstone toward the reformation of the educational scenery, thus promoting the importance of providing users with adaptive and personalised learning experiences. At the same time, the use of Augmented Reality (AR) applications in education have been gaining a growing interest across all the educational levels and contexts. However, the efforts to integrate LA techniques in immersive technologies, such as AR, are limited and scarce. This inadequacy is mainly attributed to the difficulties that govern the collection and interpretation of the primary data. To deal with this shortcoming, we present the "Augmented Reality Learning Analytics" (ARLEAN) ethical framework, tailored to the specific characteristics that AR applications have, and focused on various learning subjects. The core of this framework blends the technological, pedagogical, and psychological elements that influence the outcome of educational interventions, with the most widely adopted LA techniques. It provides concrete guidelines to educational technologists and instructional designers on how to integrate LA into their practices to inform their future decisions and thus, support their learners to achieve better results.
\end{abstract}

Keywords: augmented reality; instructional design; learning analytics; educational data mining; education

\section{Introduction}

The proliferation of information technologies in the 20th century and the commodification of the internet presents us today unique opportunity and challenges in teaching and learning. Dynamic, tailor-made, learning paths to achievement leaving no student behind will mark the democratization of high-quality student-centred education for all. Indeed, a number of contemporary approaches can support this pursuit with the aid of various computing system architectures and innovations [1]. Artificial Intelligence (AI), in the form of Machine Learning (ML) models [2], recommender systems [3], predictive learning analytics [4], Educational Data Mining (EDM) [5], and adaptive learning [6,7], allow us to apply personalised learning techniques in both physical, attendance-based, education and distance [8]. All the above-mentioned methods are fuelled by metrics and analytics around learning, namely Learning Analytics (LA). Learning Analytics are polymorphic data in diverse formats measured, collected, reported, and associated with all facets of technology-based learning such as the learners and their context [9].

What educational subjects should be personalised? Ideally, all. However, well-defined and structured learning disciplines are more attuned to algorithmic optimisation through analytic division, systemic classification, taxonomic organization, and computational analysis $[10,11]$. Contemporary education adopts an integrating logic to cultivate analytic reasoning, creative thinking, and problem-solving competence [12]. Skill competencies in 
the majority of educational settings enable tackling real-world challenges using appropriate technology by implementing engineering design based on mathematical thinking and scientific inquiry [13]. The development of higher-order and soft skills in the primary and secondary education and the encouragement of associated careers has been a priority in Europe, USA, and Asia [13-15].

Augmented Reality (AR) become really important for various learning subjects due to their capacity to contextualise knowledge, to unify content with context, and remove abstractions [16,17]. AR allows the transition from 'just-in case' learning to 'just-in-time' learning by merging the physical environment with digital, virtual elements [18]. LA in an AR context, for instance, in the form of wearable sensor data, can support expertise training for enhanced performance $[19,20]$. Analytics in conjunction with mobile devices can also be used for automatic recognition of affective states [21].

On the other hand, the use of LA in conjunction with AR raise a series of ethical concerns, risks, and ramifications for involved stakeholders. Ethical questions around AR include user safety, information overload, violation of privacy, and harmful social effects [22,23]. Ethical issues lead to wide-spread criticism against the public use of products such as smart glasses [24]. Additionally, Previous theory-based AR frameworks [25,26] have attempted to synthesize cognitive, emotional, physical, pedagogical, and technological aspects of learning. For instance, Kazanidis et al. [25] proposed the overall architecture of the proposed learning analytics (LA) framework for AR-supported instruction: (a) design of applications, (b) development and implementation of new modules, (c) analysis for the design component outcomes, and (d) assessment of any possible improvements on students' learning performance and outcomes. The same authors have also suggested two types of architecture: conceptual and technical. The former includes the identification of key stakeholders and users' needs. The latter entails from data mapping, metrics, and indicators to data analysis methods and visualization techniques using AR. Zhu et al. [26] suggested a mobile augmented reality education (MARE) conceptual design framework, which can be utilized for AR apps development in health education. As an instructional design framework, it consists of three hierarchical layers: the foundation, function, and outcome layers. It emphasizes on three learning theories, such as situated, experiential, and transformative learning and delivers several components that can be fundamental support and relationships among learning, practice, and the environment.

However, none of the above-mentioned frameworks consider the ethical considerations and implications from each stakeholders' viewpoint. The objective of this article is to present a practical, multi-dimensional LA framework with a comprehensive ethical dimension to organise user experience with AR devices for teaching and learning.

\section{Theoretical Underpinnings}

\subsection{Augmented Reality-Supported Instructional Design Methods}

A substantial body of literature [27-29] has advocated that instructional design approaches are encompassed by learning strategies (e.g., instructor-led, self-directed) and learning techniques (e.g., problem-based learning, collaborative learning). The elements of these methods and techniques assist scholars and educators to contextualise the way that the learning process is applied especially when students learn by practising (i.e., cultivation of cognitive skills like creativity, abstract thinking, problem-solving) or investigating new concepts (i.e., application of prior knowledge and experiences to new areas and domains). To this perspective, a well-designed instructional context enables the involved stakeholders (e.g., teachers, assistants) to facilitate their learners' understanding with regard to the newly provided information, how this information aligns to previous knowledge, how it can be translated to new knowledge and, finally, how such knowledge can be applied effectively into practice. Educational studies have been linking students' knowledge acquisition (i.e., learning outcomes, achievements) and performance (i.e., competencies, skills) with the range of behavioural fluctuations that learners have been experiencing during the learning process [30]. 
AR has been under serious consideration during the last decade thanks to the great affordability and potential that modern computing and mobile devices have. Although the integration of such technologies and applications usually affects the social context, in the first place, their adoption to other areas (e.g., education, training) is becoming increasingly visible with reasonably positive results [31]. It also enriches the physical environment with artificially generated information rendered over physical objects in real-time [32,33]. AR applications are designed and developed in accordance with the specifications that mobile computing devices (e.g., smartphones, tablets) have [34]. Nonetheless, this does not mean that the user experience is discounted as AR applications provide diverse ways for interaction (e.g., gesture-, gaze-, facial-, speech-recognition, real-time feedback via visual, haptic, and/or acoustic cues) [35].

The most common tracking approaches used to render digital content (e.g., 3D models, text, animations) are classified into the following broad categories [36,37]:

- Marker-less: use of geospatial data (e.g., GPS coordinates) to render information. Typical examples include learning activities that involve navigation and exploration.

- Marker-based: use of the devices' camera to capture and match the pre-registered information of physical objects or the position of AR-enabled markers (e.g., QR codes). Typical examples include learning activities that involve hands-on experimentation.

- Hybrid: a combination of both marker-less and marker-based information.

AR-supported instruction has aided the demanding needs that various education fields such as STEM (Science, Technology, Engineering and Mathematics) have by transforming a wide range of exercises and tasks. For instance, in the field of science, AR applications have been utilised to support students control of certain procedures that require hands-on actions (e.g., chemistry experiments) while also providing opportunities for reflection [38]. Abdusselam and Karal [39] explored the impact of AR on learners' studying physics subjects and found a positive influence over their intention to participate in the learning activities and engage with the exercises. The authors (ibid) further highlight the potential of AR to boost learners' performance as well as on the comfort (self-confidence) they have had during classroom discord (e.g., answering questions related to the subject under investigation). However, this contradicts the findings of Chen [40] who concluded that utilising game-based approaches with AR can improve students' learning achievements and flow states but does not necessarily promote their willingness (motivation) to practice. In Engineering, the use of AR-supported applications has enabled practitioners to simulate relevant processes by rendering, with high representational fidelity and in real-time, information emerging from the real-world [35]. To this end, a strong and growing interest over the future applications of AR in Engineering is identified both in residential and commercial projects [41].

Teaching and learning fundamental mathematic concepts under the aid of AR applications is yet another area that researchers have explored (e.g., [42]), as a means to facilitate the in-person instruction. In the scenario that the authors (ibid) presented, students could explore the virtual learning content, at their own pace, while also undertaking different learning tasks. Other typical examples related to the use of AR in mathematics instruction (inside or outside the classroom) include the measurement of the size of real-world objects or the calculation of distance [43]. Lastly, in the broader spectrum of mathematics education, Ibáñez et al. [44] have concluded that the use of AR in Geometry can greatly affect students' achievements and learning outcomes.

Similarly, AR-supported Information Technology courses have helped students to cultivate their story-design skills (e.g., length, narrative, creativity) when compared to their counterparts who utilised story cards [45]. Additionally, in Computer Science courses, learning how to program using AR applications has supported the cultivation of cognitive thinking skills such as computational thinking, problem-solving, and critical thinking [46].

In social sciences, a significant body of literature has also documented the potential of AR in education. Ok and colleagues [47] analysed the effects of video modelling using an AR apps projected on iPads in an effort to improve phonics skills of first-grade students 
with difficulties in reading. The results were very positive in terms of using AR itself, and can be improved further when AR apps are combined with other reading activities, without being lengthy. Wen et al. [48] reported that higher levels of student engagement can be achieved when they have the chance to generate their own AR artifacts at the beginning of language learning instructional settings. Additionally, the novelty effect of AR apps with animation-triggering radical cards has positively impact students' outcomes. Additionally, Harley et al. [49] investigated possible ways to improve location and tour-guide prompts for historical monuments. In the same study, authors concluded that students' outcomes using mobile AR applications reported significantly higher levels of task value after the guided tour compared to their pre-guided tour responses.

On the other side, various studies $[35,37,41]$ have noticed several drawbacks and challenges in using of AR-supported instruction, such as: (a) the processing speed of the technological equipment (hardware) especially when marker-based tracking is used, (b) the usability issues that relate to the AR ergonomics especially when using smart devices, and (c) the prerequisites related to the software development of such interventions (e.g., 3D modelling, interface design, and/or data structures).

\subsection{Ethical Issues Associated with the Use of Augmented Reality in Education}

Ethical considerations around AR applications in education include physical, psychological, moral, and data privacy concerns [50]. AR applications can distract attention from aspects of the physical world and lead to accidents, even lethal ones [51,52]. These threats to user physical safety need to be addressed with utmost care especially in cases of marker-less, location-based AR. Psychological effects include information overload due to multimodal stimuli and superrealism [23]. The fidelity of AR content is gradually becoming hyper-real and almost indistinguishable from the physical world. Similarly, experiences, positive or negative, in novel, "augmented" and mixed digital environments are of the same nature to the human brain as their counterparts in physical environments. Hence, traumatic experiences could have real mental health consequences.

On the instructional design, moral concerns include the science-grounded neutrality on controversial topics as well as the representation and comparison of multiple perspectives in debatable topics [50]. Another moral issue related to location-based AR is the unauthorized content augmentation that could lead to the violation of cultural norms. Finally, three data privacy concerns were identified in the context of AR: informational, volumetric, and physical privacy. New types of personal information can be collected through AR devices; biometric data such as facial features, reflexes, eyes, and motor movement (kinetic fingerprint). The gradual accumulation of digital and biometric data can lead to the potential compilation of personal biometric psychography [53] for commercial or other purposes. This is alarming given that even anonymized, motion tracking recorded data can be personally identifiable using AI and ML [54]. The context-aware AR captures the surrounding environments. If this private information is disseminated, it could cause a violation of volumetric privacy. Moreover, geolocation and movement tracking can breach users' physical privacy and reveal intimate personal information, e.g., their place of residence-spatial doxing [55]. Such personal identifiable data are vulnerable to abuse, whether by unauthorized actors or for irresponsible commercialization.

\subsection{Rationale and Purpose}

The massive amounts of data that modern Learning Management Systems (LMS) generate have enabled educators and instructional designers to monitor and assess their learners' needs and, subsequently, make data-informed and timely decisions related to future interventions [56]. However, despite the wide adoption of LMS, future predictions related to Web 4.0 expect that immersive technologies will play a key role on the shaping of the new societal and educational norms due to their great potential to deliver a diverse range of information to users [57]. Combining data from diverse e-learning platforms can 
facilitate the evaluation of the instructional decisions (e.g., effectiveness of the learning designs) and increase learning opportunities across distributed learning settings [58].

However, unlike Virtual Reality (VR) systems, which require large financial and time investment for the development and the deployment of the computer-generated environment, AR applications enhance the user experience with significantly lower preparation time, cost, and spatiotemporal limitations. For this reason, many attempts have been made to integrate mobile-AR in formal, informal, and non-formal contexts [44]. Accordingly, based on the similarities that VR and AR technologies have, different efforts are identified where the educational potential of such interventions is explored in accordance with the most mainstream theories and topics that relate to immersive technologies [59,60].

Even though such exploratory studies provide the foundations to evaluate and better understand the strengths and the limitations of these educational interventions, the power to generalise the outcomes of these efforts is restricted by the relatively small sample sizes of the partaking cohorts as well as the specific contexts and scientific fields in which the AR applications have been applied. However, these obstacles act as a barrier toward the future evolution of the universal digital ecosystem where a large amount of data are utilised to inform the research directions and the respective practices [37].

According to the aforementioned studies, researchers who have attempted to explore the integration of Learning Analytics (LA) and EDM techniques for immersive technologies have concluded that the unique features of such applications impose certain challenges and constraints which require careful and thorough consideration well-before the integration stage (e.g., [61,62]). This conclusion justifies the limited and spontaneous attempts that can be identified in the literature with regard to such integrations (e.g., [61,62]) and the even scarcer attempts to theorise the processes that underpin them $[60,63]$. Therefore, the present work aims to explore, classify, and detail the different sources and types of data that the involved stakeholders can retrieve from the mobile devices, the AR applications and the users per se and further propose ways and methods for their analysis and interpretation $[64,65]$.

\section{The ARLEAN Ethical Framework}

Contemporary education requires analytical thinking skills and hands-on approaches to achieve a reasonable degree of intuitiveness which is required for the learners achieve their goals. For this reason, in conjunction to the use of an LMS we propose the integration of AR technology as it can facilitate the simulation of real-world problems and support the deconstruction of the different concepts that govern these fields. In a sense, instead of forcing learners to imagine or visualise the problems under investigation, the proposed system offers them the means to undertake a simulated experience which compliments the learning process and promotes in-depth knowledge development.

However, according to Dünser and Billinghurst [66], most of the AR educational applications are one-off prototypes, developed under the 'proof of concept' notion. Such practice, however, hinders or even prevents the development of a mutual understanding regarding the common design elements and effectiveness of these alternative educational practices. Under this claim, the proposed "Augmented Reality Learning Analytics" (ARLEAN) ethical framework provides a common reference point which classifies commonly acquired input data and examines the influence that such diverse variables may have on different model implementations. Accordingly, the proposed LA system is targeting at improving the learning curve of the students by monitoring their activities and addressing the errors of the learning process. To achieve this goal, the information gathering originates from the utilised LMS, the AR application, and the self-reported psychometrics instruments. The information (abstract level) that can be collected under the consideration of each category is illustrated in Figure 1 and discussed, in greater detail, below. 


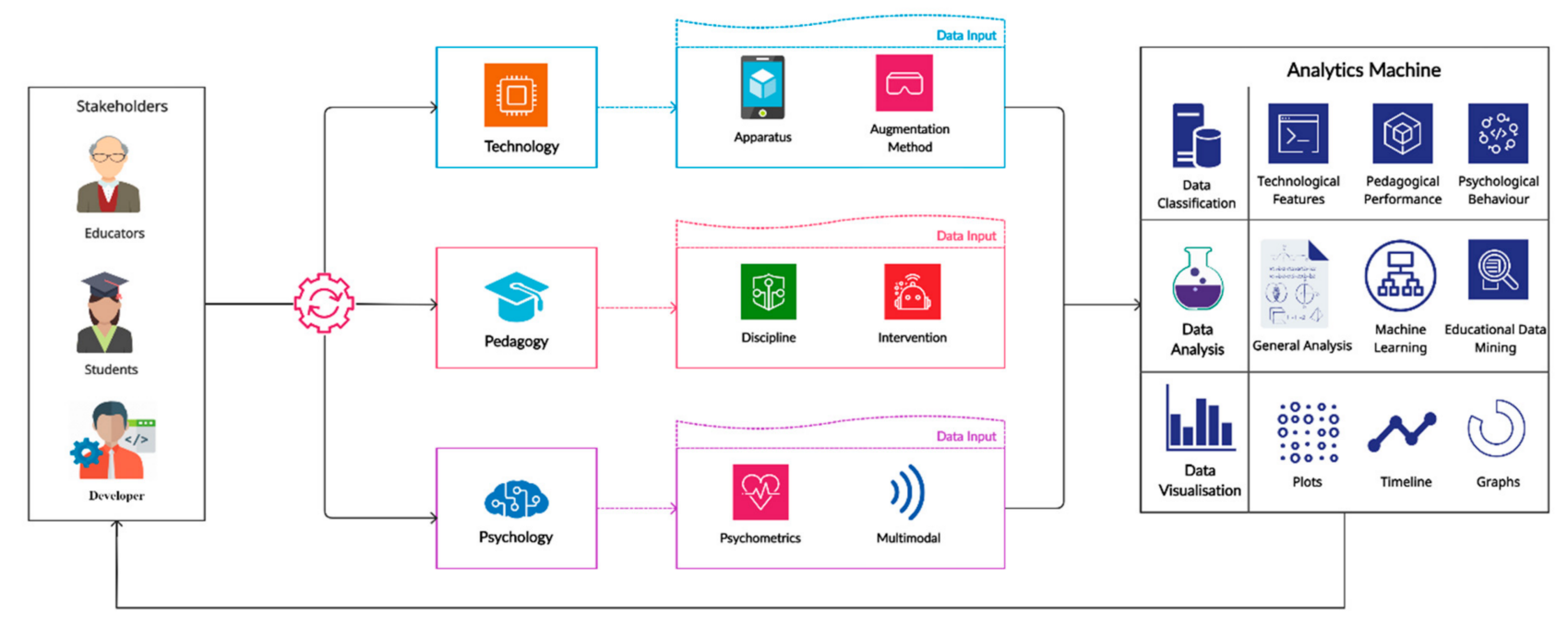

Figure 1. Overview of the Augmented Reality-Learning Analytics system.

\subsection{System Design}

The initial data input is aligned to and classified in accordance with the information that the key stakeholders can provide. Given the iterative nature of LA, it was deemed necessary to create a loop which would allow the engaged parties to feed the system with information related to their main duties or tasks and in return acquire insights relevant to the areas that they are mostly interested (Supplementary Materials, Table S1). With that in mind, the present LA system classifies the data input into the following pertinent categories:

\section{- Technology}

In this category we consider the aspects related to the technological apparatus utilised to deliver the AR content and the respective enablers that allow for the subsequent evaluation of the system's usability/user experience. The main stakeholders responsible for these decisions are the software developers and the educators who are in charge of the intervention. Their main duty is to decide what values (data-information) will be assessed in view of both the available general purpose technical equipment (e.g., desktop PC, laptop, smartphone, internet speed), the AR wearable gadgets (AR lenses, AR glasses, smartwatch, headsets), and the augmentation approach (e.g., physical objects, QR codes/markers, tabletops). Such kind of data are retrieved from the software's system logs, the sensors of the AR gadgets and the inherent data collection features that modern 'smart' devices offer. The analysis of such information enables educational technologists and instructional designers to develop a better understanding of students' reactions to different types of stimuli under controlled (e.g., classroom) and uncontrolled (e.g., home) circumstances. Moreover, it enables the interested parties to identify shortcomings/drawbacks of the integrated solution so that additional modifications and/or improvements can be made to improve learners' educational experience.

\section{- Pedagogy}

In this category we take into account the educational domain under consideration (e.g., Science, Technology, Engineering, Mathematics, Arts) and the pedagogical approaches utilised for the didactic of the concepts/subjects under investigation (e.g., observation, problem solving, experimentation, content creation) so as to evaluate learners' performance and knowledge acquisition. Data that can support the attainment of such objective emerge from the hardware equipment utilised for the conduct of the augmentation combined with information originating from the integrated LMS (system logs). Accordingly, the gathered information can be processed using inferential statistics and machine learning algorithms. The analysis of such information enables teachers and teacher assistants to create a better understanding of students' performance (e.g., summative or formative assessments), difficulties (e.g., knowledge gaps, misconceptions), and competences (e.g., skill development, 
knowledge acquisition). Moreover, it enables students to track their own learning outcomes and explore problematic/difficult learning topics that require attention.

\section{- Psychology}

In this category we focus on the collection of psychological data that influence learners' educational experience with the AR software (e.g., motivation, engagement in the learning process). The data required for such evaluation originate from the distribution of psychometric instruments (e.g., surveys related to the user experience or the degree of learning satisfaction, participants' demographics) combined with the information emerging from the sensors of the utilised (AR) wearable devices (e.g., eye tracking, facial expressions, gesture tracking, noise levels, heart rate, skin conductivity) so as to explore students' intention to use the AR software. The analysis of such multidimensional data can be achieved via ML and EDM techniques in accordance to the needs of the respective stakeholders. The processed information can be utilised to compliment further the evaluation of the educational interventions and thus, provide the senior stakeholders with insights related to learner engagement (e.g., concentration, focus) and motivation (e.g., intention to complete the given tasks or time spent on different tasks).

Upon creating the stakeholders' profiles, users' actions, and interactions with the digital tools (i.e., the LMS, the AR app, third-party equipment) are recorded, monitored, and updated consistently. Subsequently, diverse ML algorithms and EDM techniques are utilised to measure and identify associations among different variables. In doing so, a negative feedback loop—which can eliminate the poor practices of instruction-is created and so does a positive feedback loop, which highlights the behaviours that correlate to better performance. These associations are then employed to make predictions about the students' performance and suggestions on the best course of action to improve their learning curve. The interested stakeholders can get hold of this information via the LMS which displays the particular findings via statistical graphs, timelines, data plots, score values and so on.

By integrating such a universal system, the future development decisions of the instructional designers (e.g., intervention design, and content creation) are data-driven and context-specific while the educational practices of the teachers (i.e., didactic approach and instructional methods) can be optimised both in accordance with the cohort's preferences and to the needs of the individuals. Finally, by offering learners insights about their learning progression and hints on how to improve their learning practices, the overall educational experience becomes more efficient and effective.

\subsection{System Development}

In this section we present and detail the key features, elements and functions of the proposed system which are broken down into the following components:

\section{- Data Classification}

The collected data are pipelined to the LA machine which is responsible for the classification of the input variables. In the first category (technological features) the system clusters information emerging from the utilised technological devices. In greater detail, data generated from the students' interaction with the LMS include engagement time with the exercises, instructional objectives of the exercises, and assessment scores. Data generated from the mobile phones relate to the AR application (e.g., frequency of use, interaction time), the physical environment (e.g., location tracking, noise levels), and students' actions (e.g., gestures' tracking, eye movement, facial expressions) while using the AR learning tool. In the second category (pedagogical performance) the system clusters information related to the scientific discipline, the characteristics educational intervention (e.g., overall duration, learning objectives, difficulty levels of the exercises, number of assessment points), and information related to students' profile (e.g., demographics, GPA). The final division (psychological behaviour) the system clusters information emerging from psychometric tests (e.g., UX surveys, learning satisfaction) and sensors (e.g., stress, temperature). 


\section{- Data Analysis}

For the analysis of the gathered information a combination of statistical analysis techniques as well as ML and EDM algorithms is employed. For the initial classification, the Naïve Bayes approach is utilised to perform the first clusters of the raw data followed by multiple regression analysis which supports the identification of the impact that each variable has against the testing hypothesis. Finally, in order to identify the best course of action, a set of conditional control statements are introduced using the Decision Tree classification method.

For the integration of the abovementioned analyses, the TensorFlow library is utilised to perform regression analysis and module prediction using different input data from seemingly uncorrelated variables. Accordingly, platforms such as the AIHS and ITS are used to build adaptive models required for the personalisation of the learning experience.

\section{- Data Visualisation}

The analysed results and system recommendations are used to evaluate trends and make predictions about the success of the intervention. The dissemination of these outcomes to the stakeholders is made via the LMS in diverse ways (e.g., graphs, maps, timelines). Below, we provide indicative examples related to the ways that the findings can be communicated:

a. Information related to the instructional tools-including the usage patterns followed in the LMS or the AR application-are expressed via timeline graphs (e.g., engagement time correlated to tasks performed).

b. Information related to the educational intervention-such as learning outcomes or engagement time-are expressed via heatmaps (i.e., expected outcome correlated to actual results).

c. Information related to the personalised learning path—such as knowledge acquisition and retention-are expressed via statistical graphs (i.e., pre-intervention knowledge correlated to post-intervention knowledge).

d. Information related to participants' behaviour-such as learners' preferences over specific exercises, learning motivation-are expressed via an interaction matrix (i.e., recommendations for learning material/exercises based on former activities).

On the grounds of these analyses, the involved stakeholders can then make any amendments required to the digital instruction tools and improvements on the study materials. At the same time, learners can utilise the personalised recommendations to work on the areas that require improvement or advancement.

\subsection{Ethical Layer}

To design the ethical layer of the LA system, we followed recommendations from the theories of Value Sensitive Design (VSD) and Life-Based Design (LBD). VSD encourages designers to take into account all ethical and moral issues from the use of new educational systems and iterate to address all problems that might arise [49]. LBD focuses on the position of technology in human life and suggests a four-phase analysis to guide the early design thinking for products and services [67].

The outlined ethical issues associated with the use of AR in education can be clustered across four classes: physical, psychological, moral, and data privacy. These issues, due to their varying natures, depend on different stakeholders and can be prevented at four different stages in their life cycle. For instance, moral concerns regarding the content of an immersive experience can only be determined primarily by the involved instructional designer. Other stakeholders include government, developers, and users. Local, regional or national legal bodies can determine who has the right to augment content in a specific geographic location, public or private. A summary of all identified AR ethical concerns is provided in Figure 2 and Table S1. 


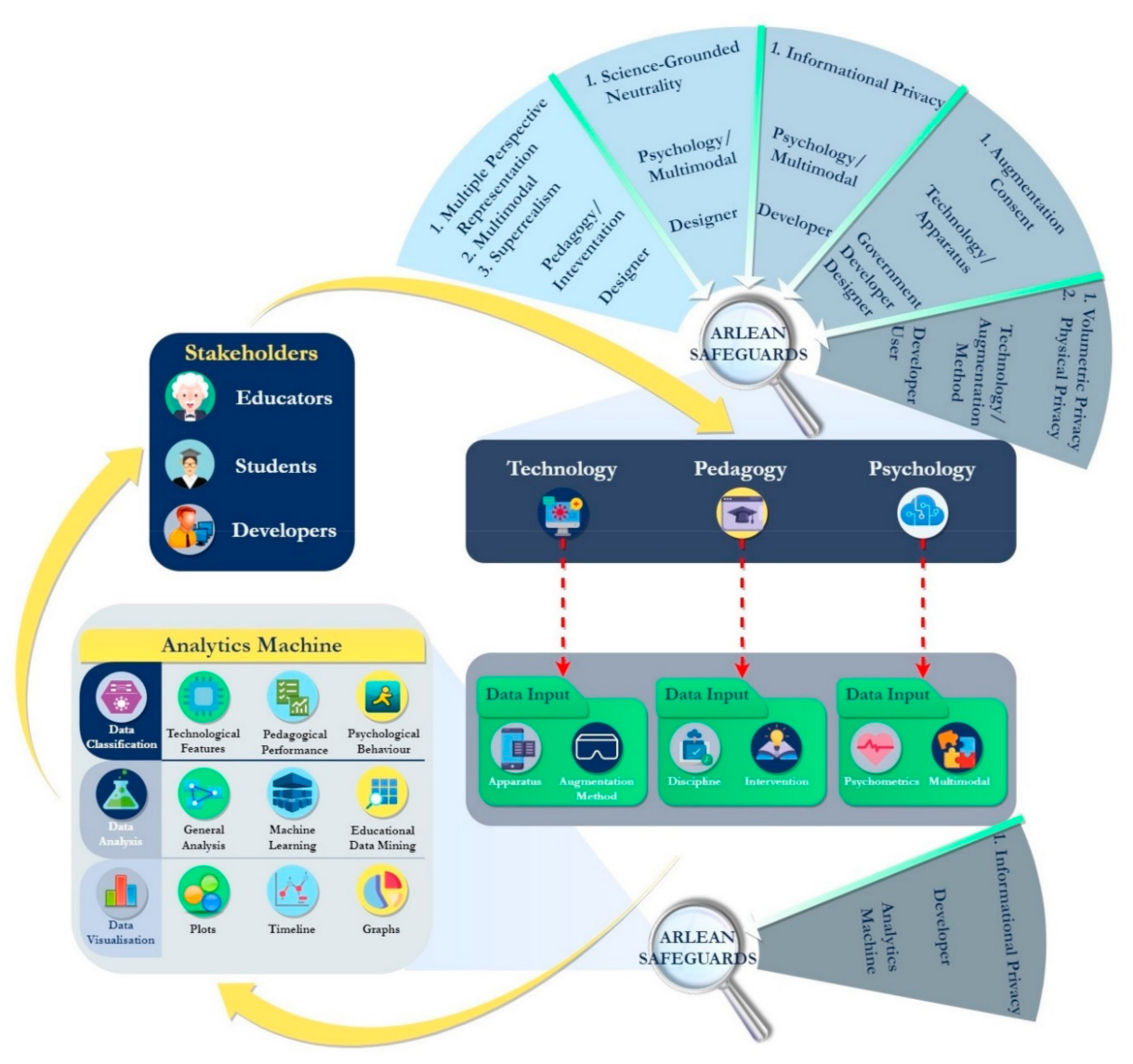

Figure 2. Overview of the 'ARLEAN' system.

These issues can be prevented by applying a set of principles. For instance, biometric data containing health and medical information should be collected, processed locally, and discharged [55]. User data must also be stored in accordance with the General Data Protection Regulation (GDPR (Available online: https://gdpr.eu/what-is-gdpr/, accessed on 24 March 2021)) established by the European Union. The GDPR was enacted on 25 May 2018. The GDPR provisions are the toughest data privacy and security regulations in the world. Penalties for violating the GDPR and compromising data privacy and security can be as much as tens of millions of euros. Additionally, inferences about users' behaviour beyond learning performance should be avoided and, in any case, coding parameters should be communicated transparently to everyone affected. Finally, supporting user control on users' own data and identity (i.e., what is known as a self-sovereign identity) will further prevent hacking and theft of personal volumetric and geolocation data beyond adherence to the GDPR principles and the XR Ethics Manifesto provisions [53].

Physical (attentional distraction), psychological (multimodal stimuli, superrealism), and moral matters (science-grounded neutrality, multiple perspectives representation, augmentation consent) cannot be affected from the LA perspective. On the other hand, from the LA standpoint, data-related ethical issues can be met with certain safeguards. For the scope of this paper, we will focus on the ethical concerns that can be prevented at the system architecture level (developer), primarily related to data privacy.

Data-related ethical issues in the application of AR to LA pertain to privacy, where data collected is vast in both scale and granularity [68]. Certain safeguards can be applied to data-related ethical issues to eliminate them. These safeguards can be motivated both by deontological aspects such as 'principles of action' and 'duty to society' as well as a consequentialist perspective that takes into account the consequences of these safeguards to ensure privacy. The safeguards for ethical issues are needed because algorithms are driven by data, while learning is driven by theories. Therefore, the safeguards must, in 
general, strike a balance between asking students for more data and imposing limitations on data collection. Furthermore, all phases of the intervention design (data management layer) must be developed with LA ethics in mind. Tzimas and Demetriadis [68] proposed a checklist of LA ethics taking into account the informational, volumetric, and physical privacy considerations, in addition to other ethical issues outside the scope of this work. Precisely, the authors [68] propose six guidelines for privacy: (1) communicate with stakeholders information about the data collection and the individuals or groups of individuals who have access to data, (2) contract with external vendors in ways that uphold privacy, (3) application of the GDPR principles, (4) employment of two-factor authentication and authorization methods, (5) evaluation of the data protection procedures from a data protection specialist, and (6) provision of training to the instructional designers on ethical aspects of data privacy and security.

These safeguards can be instituted on the developer side and also on the user side (e.g., by offering opt-outs for the collection of LA data). All stakeholders-students, teachers, instructional designers, institutions, industrial agents—should be involved. Voluntary consent is essential for LA ethics, as is an understanding that the data generated must be interpreted and applied in the proper educational context, in line with theories of effective learning. Student data should also not be sold. Learners should have the right for their data to be removed from the system after a given period of time while institutions oversee this entire process.

In an effort to expand the aforementioned guidelines, we compile a list of the privacyrelated (informational, volumetric, physical) safeguards that can be integrated in the proposed LA:

Informational privacy refers to the increasing size of the digital footprint. This can include any data collected by the software, including biometrics information, behavioural inferences, emotion analysis and harvesting, and algorithmic bias. The developer can ensure informational privacy by including safeguards to protect personally identifying data increasingly used in AR LA applications, such as by anonymization of data and an opt-out feature for users who do not wish to share their data for LA purposes. Without taking into account the data management aspect of LA ethics, stakeholders may mistrust and therefore, not engage with these services.

Another ethics consideration of the vast amount of information generated is that providing feedback to students can be a challenge. It is important that feedback provided does not end up discouraging students. They should not be labelled in ways that affect their physical, mental, and emotional well-being As Tzimas and Demetriadis [68] argued, "the key is to check for intellectual freedom, ensure individuality, and avoid labelling and surveillance" (p. 1122). Therefore, modelling LA feedback in accordance with learning design theories can help make students more engaged and active and make the teaching more effective.

A third challenge in informational privacy concerns the amount and the degree of users' personal information (data trails) that can be pre-obtained from non-educational resources [67]. While algorithms are more powerful when they have more information, this can also backfire from an ethics standpoint, if non-authorised stakeholders gain access to the information or if such information used without consent (e.g., for research purposes by corporations or even government agencies). Yuste and colleagues [69] recommend that, for biometric data, such as neural data, "the ability to opt-out of sharing should be the default choice".

In terms of safeguarding against surveillance, volumetric privacy, and physical privacy risks, which both have a location-based component, can be mitigated by both developer and user. Physical privacy relates to the use of geolocation technologies in LA applications using AR. The main risk is spatial doxing, or the leaking of one's location information, which can pose a physical safety risk for the user. Physical privacy risks can often be mitigated by the user, who can opt-out of location sharing. However, physical privacy risks can also be reduced on the developer side, by limiting data collection to reduce surveillance. Developer-side safeguards will help boost trust and improve the 
adoption of the LA tools. The European Data Protection Supervisor (Available online: https:/ / edps.europa.eu/en, accessed on 20 April 2021) recommends not collecting location data unless it is needed for a specific use. While the risks of location data gathering may not be an immediate threat, it may generate cultural issues down the line-creating a 'digital and cultural data trespassing' which defies norms of privacy ethics and would require additional safeguarding later on [70].

\section{Discussion and Conclusions}

The present work demonstrates how extended reality technologies, such as AR, combined with LA can significantly enhance evidence-based personalised learning by reflecting users' individual choices, preferences, needs, and performance as well as the effectiveness of the instructional approach. The proposed model considers the needs of the various stakeholders (teachers, students, and developers) by collecting data emerging: (a) from the use of the technological apparatus, (b) the perception of the engaged users to the instructional stimuli, and (c) their psychological-emotional responses and collectively analyses them via a custom LA machine. Moreover, the system is integrating a layer of ethical safeguards that protects students' safety, privacy, and well-being. In this way, ethics-informed technological systems can achieve a more widespread adoption.

As indicated by the main framework both the socio-cognitive and the technical factors can play a significant role on how and under what circumstances educators and scholars can utilise immersive technologies by considering ethics over time. As educators and researchers, we propose our experience based on the ethical factors that affect typical educational institutors across the various disciplinary contexts $[6,25]$. To widen out this effort, we aggregated the most essential and crucial ethical factors, from the developmental point of view, and proposed an ethical practical framework.

The current work adds to the corpus of knowledge the ethical factors that could have an impact on both students and instructor's experience in view of integrating AR technology. Specifically, we identified various ethical issues in AR usage that have not been well-documented in the relevant literature. These include a variety of personal factors (e.g., potential threats) and classification issues (e.g., psychological, physical, moral), desires to strengthen and understand better any relationships respecting the broader socio-cognitive and socio-cultural school contexts, in which the educational community is entailed. While the discussion pertaining to these issues is appeared in the broader literature examining AR-supported issues c.f., [44,48], this work contributes by presenting and suggesting the effect of an ethical framework that these tensions have on educators' and scholars' practices. As educators and scholars strive hard to identify the use of innovative platforms to apply theory into practice and as they cope with both social and cognitive pressures to use them purposefully, it behoves researchers to take an expansive view of the AR use beyond its potential and added-value in education.

Notwithstanding the foregoing, some of the elements and the respective ethical considerations that have been explored and discussed in the proposed framework are also applicable to the wider spectrum of Mobile-Learning (e.g., applications that offer interactive educational content, multimedia-based exercises). Therefore, developers, instructional designers, and educators who are willing to evaluate the potential of mobile-based educational apps, via Learning Analytics, are advised to consider the provided guidelines and adapt their practices accordingly.

Future work involves an elaborated work plan to implement and evaluate the proposed ARLEAN model in the following stages:

1. Review of ethics research in VR and AR;

2. Identification, assessment and selection of practical methods to address ethical issues and potential moral threats recorded in Table 1;

3. Implementation of a working ARLEAN prototype;

4. Evaluation of the efficacy of the ARLEAN prototype. 
Table 1. Ethical issues associated with AR use in education.

\begin{tabular}{|c|c|c|c|c|c|c|}
\hline$\#$ & $\begin{array}{l}\text { Ethical Issues } \\
\text { (AR) }\end{array}$ & Classification & $\begin{array}{l}\text { Potential } \\
\text { Threats }\end{array}$ & Cases (AR) & $\begin{array}{l}\text { Prevention } \\
\text { Level }\end{array}$ & ARLEAN Layer \\
\hline 1 & $\begin{array}{l}\text { Attention } \\
\text { distraction }\end{array}$ & Physical & $\begin{array}{l}\text { Harm to safety } \\
\text { Accidents }\end{array}$ & $\begin{array}{l}\text { Markerless } \\
\text { Location- } \\
\text { based }\end{array}$ & $\begin{array}{l}\text { Designer } \\
\text { User }\end{array}$ & - \\
\hline 2 & $\begin{array}{l}\text { Multimodal } \\
\text { stimuli }\end{array}$ & Psychological & $\begin{array}{l}\text { Information } \\
\text { overload (e.g., } \\
\text { persuasive } \\
\text { advertisement) }\end{array}$ & All & Designer & Pedagogy/Intervention \\
\hline 3 & Superrealism & Psychological & $\begin{array}{c}\text { Traumatic } \\
\text { experiences } \\
\text { (e.g., immersive } \\
\text { violence) }\end{array}$ & All & Designer & Pedagogy/Intervention \\
\hline 4 & $\begin{array}{l}\text { Science- } \\
\text { grounded } \\
\text { neutrality }\end{array}$ & Moral & $\begin{array}{l}\text { Indoctrination } \\
\text { Manipulation } \\
\text { Sensory } \\
\text { information } \\
\text { misinterpreted } \\
\text { as truth }\end{array}$ & All & Designer & Psychology/Multimodal \\
\hline 5 & $\begin{array}{l}\text { Multiple } \\
\text { perspectives } \\
\text { representation }\end{array}$ & Moral & $\begin{array}{l}\text { Memory hole } \\
\text { Bias }\end{array}$ & All & Designer & Pedagogy/Intervention \\
\hline 6 & $\begin{array}{l}\text { Augmentation } \\
\text { consent }\end{array}$ & Moral & $\begin{array}{l}\text { Unauthorised } \\
\text { augmentation } \\
\text { Normative } \\
\text { standards } \\
\text { violation }\end{array}$ & $\begin{array}{l}\text { Markerless } \\
\text { Location- } \\
\text { based }\end{array}$ & $\begin{array}{l}\text { Government } \\
\text { Developer } \\
\text { Designer }\end{array}$ & Technology/Apparatus \\
\hline 7 & $\begin{array}{l}\text { Informational } \\
\text { privacy } \\
\text { (increasing size } \\
\text { of digital } \\
\text { footprint) }\end{array}$ & Data privacy & $\begin{array}{c}\text { Biometric } \\
\text { psychography, } \\
\text { Behavioral } \\
\text { inferences, } \\
\text { Emotion } \\
\text { harvesting, } \\
\text { Algorithmic } \\
\text { bias }\end{array}$ & All & Developer & $\begin{array}{c}\text { Psychhology/Psychometrics/ } \\
\text { Analytics Machine }\end{array}$ \\
\hline 8 & $\begin{array}{l}\text { Volumetric } \\
\text { privacy }\end{array}$ & Data privacy & $\begin{array}{c}\text { Volumetric } \\
\text { space capturing }\end{array}$ & $\begin{array}{l}\text { Markerless } \\
\text { Location- } \\
\text { based }\end{array}$ & $\begin{array}{l}\text { Developer } \\
\text { User }\end{array}$ & $\begin{array}{c}\text { Technology/Augmentation } \\
\text { Method }\end{array}$ \\
\hline 9 & $\begin{array}{l}\text { Physical } \\
\text { privacy } \\
\text { (movement } \\
\text { monitoring- } \\
\text { geolocation) }\end{array}$ & Data privacy & Spatial doxxing & $\begin{array}{l}\text { Markerless } \\
\text { Location- } \\
\text { based }\end{array}$ & $\begin{array}{l}\text { Developer } \\
\text { User }\end{array}$ & $\begin{array}{c}\text { Technology/Augmentation } \\
\text { Method }\end{array}$ \\
\hline
\end{tabular}

Precisely, in the first stage we will review the field's state-of-the-art in various educational contexts of public human activity, e.g., [71]. In the second phase, we will assess the feasibility of theoretically proposed solutions such as homomorphic encryption and de-identification of personally identifiable data [55]. Third, the working prototype will involve an existing multi-awarded educational LMS [1]. Finally, the evaluation will be organised in the framework of the world-class Finnish primary and secondary school education [72] according to the guidelines of Value Sensitive Design and Life-Based Design (LBD) $[49,67]$.

Conclusively, this work raises important questions for learning practices and policy support. AR-supported instruction policies should focus on protecting students' and 
instructors' ethical dilemmas and factors that can prevent participating in AR-supported instructional contexts. Yet, it establishes that educators' and scholars' decisions should be related to the ethics that every AR application may include consisting of several factors which should be considered as early as the design stage. Therefore, a number of predefined factors are proposed to be considered as countermeasures of the several complexities that can be raised by using AR. Regarding the GDPR, it is important to consider changes over time, like policy reports that may need to be specific for scholars' and instructors' participation. In other words, as researchers and educators, we should ponder any policies within particular school contexts and disciplines and adopt an awareness that should inimitably be thoughtful of specific learning tasks, instructional contexts, norms, and values. Future studies can also consider the application of ethical safeguards beyond the technology level (e.g., pedagogical or psychological point of view) as they are interrelated and interconnected.

\section{Implications}

As previous reviews report $[33,37]$, the wide proliferation of AR technology has brought immense potential in education. The current work seeks to conceal the use of AR technology in teaching and learning by underlying the ethical considerations that govern such practices. In addition, it provides recommendations-contextualised under the proposed LA framework - which account for the multifaceted aspects of education (i.e., pedagogy, psychology, technology) and align them to the multidimensional nature of immersive technologies and educational disciplines.

From the educator's and educational technologist's perspective the following implications for practice and/or policy are proposed:

- Educators and instructors need to be trained and informed before about the educational potential of AR and its related ethical considerations.

- Even if predefined rules are applied during the development phase to mitigate the ethical issues that may arise, application developers should also consider the pilot testing of the applications so that additional feedback and recommendations can be acquired by the end-users.

- The integration of LA practices, especially when reaching a large sample scale, can highlight the various socio-cognitive and socio-cultural effects that impact students' motivation and engagement as well as learning outcomes and achievements. The interpretation of such information can provide additional insights about the widely adopted 'best-practices' and, accordingly, enable the involved stakeholders to inform their instructional methods.

The ethics in AR, while complex, remain to be explored in depth with empirical and systematic research efforts. Several privacy ethics safeguards have been recommended above, with the ability to opt-out of data collection and analytics as the paramount value to avoid malicious or unwanted use of data, and to improve participation and trust in the learning process. A limitation of the present work is the absence of consideration of matters related to the cultural safeguards needed. Therefore, future works can explore this direction and propose solutions pertinent to the cultural and/or societal differences that may affect the wide adoption of AR-enabled educational interventions.

Supplementary Materials: The following are available online at https:/ / www.mdpi.com/article / 10.3390 / computers10080092/s1, Table S1: Overview of the operational elements of the proposed AR-supported LA system.

Author Contributions: Conceptualization, A.C. and S.M.; methodology, N.P.; software, A.C.; validation, A.C., S.M. and N.P.; formal analysis, M.-J.L.; investigation, A.C.; resources, N.P.; data curation, S.M.; writing-original draft preparation, A.C., S.M. and N.P.; writing—review and editing, M.-J.L.; visualization, A.C.; supervision, M.-J.L.; project administration, A.C.; funding acquisition, M.-J.L. All authors have read and agreed to the published version of the manuscript.

Funding: This research received no external funding. 


\section{Data Availability Statement: Not applicable.}

Conflicts of Interest: The authors declare no conflict of interest.

\section{References}

1. Christopoulos, A.; Kajasilta, H.; Salakoski, T.; Laakso, M.-J. Limits and Virtues of Educational Technology in Elementary School Mathematics. J. Educ. Technol. Syst. 2020, 49, 59-81. [CrossRef]

2. Giannakos, M.; Voulgari, I.; Papavlasopoulou, S.; Papamitsiou, Z.; Yannakakis, G. Games for Artificial Intelligence and Machine Learning Education: Review and Perspectives. In Non-Formal and Informal Science Learning in the ICT Era; Giannakos, M., Ed.; Springer: Singapore, 2020; pp. 117-133. [CrossRef]

3. Torres-Ruiz, M.; Mata, F.; Zagal, R.; Guzmán, G.; Quintero, R.; Moreno-Ibarra, M. A recommender system to generate museum itineraries applying augmented reality and social-sensor mining techniques. Virtual Real. 2020, 24, 175-189. [CrossRef]

4. Herodotou, C.; Naydenova, G.; Boroowa, A.; Gilmour, A.; Rienties, B. How Can Predictive Learning Analytics and Mo-tivational Interventions Increase Student Retention and Enhance Administrative Support in Distance Education? J. Learn. Anal. 2020, 7, 72-83.

5. Romero, C.; Ventura, S. Educational data mining and learning analytics: An updated survey. Wiley Interdiscip. Rev. Data Min. Knowl. Discov. 2020, 10, 1355. [CrossRef]

6. Christopoulos, A.; Pellas, N.; Laakso, M.-J. A Learning Analytics Theoretical Framework for STEM Education Virtual Reality Applications. Educ. Sci. 2020, 10, 317. [CrossRef]

7. Xie, H.; Chu, H.-C.; Hwang, G.-J.; Wang, C.-C. Trends and development in technology-enhanced adaptive/personalized learning: A systematic review of journal publications from 2007 to 2017. Comput. Educ. 2019, 140, 103599. [CrossRef]

8. Zhang, L.; Basham, J.D.; Yang, S. Understanding the implementation of personalized learning: A research synthesis. Educ. Res. Rev. 2020, 31, 100339. [CrossRef]

9. Gašević, D.; Dawson, S.; Siemens, G. Let's not forget: Learning analytics are about learning. TechTrends 2015, 59, 64-71. [CrossRef]

10. Chen, L.; Yoshimatsu, N.; Goda, Y.; Okubo, F.; Taniguchi, Y.; Oi, M.; Konomi, S.; Shimada, A.; Ogata, H.; Yamada, M. Direction of collaborative problem solving-based STEM learning by learning analytics approach. Res. Pract. Technol. Enhanc. Learn. 2019, 14, 1-28. [CrossRef]

11. Monroy, C.; Rangel, V.S.; Whitaker, R. A Strategy for Incorporating Learning Analytics into the Design and Evaluation of a K-12 Science Curriculum. J. Learn. Anal. 2014, 1, 94-125. [CrossRef]

12. Priemer, B.; Eilerts, K.; Filler, A.; Pinkwart, N.; Rösken-Winter, B.; Tiemann, R.; Zu Belzen, A.U. A framework to foster problemsolving in STEM and computing education. Res. Sci. Technol. Educ. 2020, 38, 105-130. [CrossRef]

13. Kelley, T.R.; Knowles, J. A conceptual framework for integrated STEM education. Int. J. Stem Educ. 2016, 3, 11. [CrossRef]

14. Caprile, M.; Palmén, R.; Sanz, P.; Dente, G. Encouraging STEM Studies. Labour market situation and comparison of practices targeted at young people in different member states. Eur. Parl. 2015. [CrossRef]

15. So, H.-J.; Jong, M.; Liu, C.-C. Computational Thinking Education in the Asian Pacific Region. Asia-Pac. Educ. Res. 2020, 29, 1-8. [CrossRef]

16. Christopoulos, A.; Conrad, M.; Shukla, M. The added value of the hybrid virtual learning approach: Using virtual envi-ronments in the real classroom. In Integrating Multi-User Virtual Environments in Modern Classrooms; IGI Global: Hershey, PA, USA, 2018; pp. 259-279.

17. Pellas, N.; Mystakidis, S.; Kazanidis, I. Immersive Virtual Reality in K-12 and Higher Education: A systematic review of the last decade scientific literature. Virtual Real. 2021, 1-27. [CrossRef]

18. Mystakidis, S.; Christopoulos, A.; Pellas, N. A Systematic Mapping Review of Augmented Reality Applications to support STEM Learning in Higher Education. Educ. Inf. Technol. 2021, in press. [CrossRef]

19. Koren, I.; Klamma, R. Community Learning Analytics with Industry 4.0 and Wearable Sensor Data. In Immersive Learning Research Network; Beck, D., Allison, C., Morgado, L., Pirker, J., Khosmood, F., Richter, J., Gütl, C., Eds.; Springer International Publishing: Cham, Switzerland, 2017; pp. 142-151.

20. Limbu, B.; Fominykh, M.; Klemke, R.; Specht, M.; Wild, F. Supporting Training of Expertise with Wearable Technologies: The WEKIT Reference Framework. In Mobile and Ubiquitous Learning: An International Handbook; Yu, S., Ally, M., Tsinakos, A., Eds.; Springer: Singapore, 2018; pp. 157-175. [CrossRef]

21. Francisti, J.; Balogh, Z. Identification of Emotional States and Their Potential. In Advances in Computer Communication and Computational Sciences; Bhatia, S.K., Tiwari, S., Mishra, K.K., Trivedi, M.C., Eds.; Springer: Singapore, 2019 ; pp. $687-696$.

22. Hofmann, B.; Haustein, D.; Landeweerd, L. Smart-Glasses: Exposing and Elucidating the Ethical Issues. Sci. Eng. Ethics 2016, 23, 701-721. [CrossRef]

23. Slater, M.; Gonzalez-Liencres, C.; Haggard, P.; Vinkers, C.; Gregory-Clarke, R.; Jelley, S.; Watson, Z.; Breen, G.; Schwarz, R.; Steptoe, W.; et al. The Ethics of Realism in Virtual and Augmented Reality. Front. Virtual Real. 2020, 1, 1. [CrossRef]

24. Ajmi, A.; Robak, M.J. Google Glass for the educator: A postmortem separating the reality from the hype and some thoughts for Google. Comput. Libr. 2015, 35, 12-15. Available online: http://papers.ssrn.com/sol3/papers.cfm?abstract_id=2671420 (accessed on 1 May 2016).

25. Kazanidis, I.; Pellas, N.; Christopoulos, A. A Learning Analytics Conceptual Framework for Augmented Reality-Supported Educational Case Studies. Multimodal Technol. Interact. 2021, 5, 9. [CrossRef] 
26. Zhu, E.; Lilienthal, A.; Shluzas, L.A.; Masiello, I.; Zary, N.; Chidzambwa, L.; Zhang, M.; Kleinert, R.; Liaw, S.Y. Design of Mobile Augmented Reality in Health Care Education: A Theory-Driven Framework. JMIR Med. Educ. 2015, 1, e10. [CrossRef]

27. Akdeniz, C. Instructional Strategies. In Instructional Process and Concepts in Theory and Practice: Improving the Teaching Process; Springer: Berlin/Heidelberg, Germany, 2016; pp. 57-105.

28. Bagdonis, A.; Salisbury, D. Development and validation of models in instructional design. Educ. Technol. 2014, $34,26-32$.

29. Botturi, L.; Derntl, M.; Boot, E.; Figl, K. A Classification Framework for Educational Modeling Languages in Instruc-tional Design. In Proceedings of the 6th IEEE International Conference on Advanced Learning Technologies, Kerkrade, The Netherlands, 5-7 July 2006; pp. 1216-1220.

30. Moore, A.; Daniel, B.; Leonard, G.; Regenbrecht, H.; Rodda, J.; Baker, L.; Mills, S. Comparative usability of an aug-mented reality sandtable and 3D GIS for education. Int. J. Geogr. Inf. Sci. 2019, 34, 229-250. [CrossRef]

31. Christopoulos, A.; Conrad, M.; Shukla, M. Increasing student engagement through virtual interactions: How? Virtual Real. 2018, 22, 353-369. [CrossRef]

32. Azuma, R.T. A Survey of Augmented Reality. Presence Teleoper. Virtual Environ. 1997, 6, 355-385. [CrossRef]

33. Sirakaya, M.; Sirakaya, D.A. Augmented reality in STEM education: A systematic review. Interact. Learn. Environ. 2020, 1-14. [CrossRef]

34. Pellas, N.; Kazanidis, I.; Palaigeorgiou, G. A systematic literature review of mixed reality environments in K-12 education. Educ. Inf. Technol. 2020, 25, 2481-2520. [CrossRef]

35. Egger, J.; Masood, T. Augmented reality in support of intelligent manufacturing-A systematic literature review. Comput. Ind. Eng. 2020, 140, 106195. [CrossRef]

36. Nadeem, M.; Chandra, A.; Livirya, A.; Beryozkina, S. AR-LabOr: Design and Assessment of an Augmented Reality Application for Lab Orientation. Educ. Sci. 2020, 10, 316. [CrossRef]

37. Pellas, N.; Fotaris, P.; Kazanidis, I.; Wells, D. Augmenting the learning experience in primary and secondary school education: A systematic review of recent trends in augmented reality game-based learning. Virtual Real. 2019, 23, 329-346. [CrossRef]

38. Woźniak, M.P.; Lewczuk, A.; Adamkiewicz, K.; Józiewicz, J.; Malaya, M.; Ladonski, P. ARchemist: Aiding Experimental Chemistry Education Using Augmented Reality Technology. In Proceedings of the Extended Abstracts of the 2020 CHI Conference on Human Factors in Computing Systems, Honolulu, HI, USA, 25-30 April 2020; pp. 1-6. [CrossRef]

39. Abdusselam, M.S.; Karal, H. The effect of using augmented reality and sensing technology to teach magnetism in high school physics. Technol. Pedagog. Educ. 2020, 29, 407-424. [CrossRef]

40. Chen, C.-H. Impacts of augmented reality and a digital game on students' science learning with reflection prompts in multimedia learning. Educ. Technol. Res. Dev. 2020, 68, 3057-3076. [CrossRef]

41. Noghabaei, M.; Heydarian, A.; Balali, V.; Han, K. Trend Analysis on Adoption of Virtual and Augmented Reality in the Architecture, Engineering, and Construction Industry. Data 2020, 5, 26. [CrossRef]

42. Kazanidis, I.; Pellas, N. Developing and assessing Augmented Reality applications for Mathematics with trainee instruc-tional media designers: An exploratory study on user experience. J. Univ. Comp. Sci. 2019, 25, 489-514. [CrossRef]

43. Bujak, K.R.; Radu, I.; Catrambone, R.; MacIntyre, B.; Zheng, R.; Golubski, G. A psychological perspective on augmented reality in the mathematics classroom. Comput. Educ. 2013, 68, 536-544. [CrossRef]

44. Ibáñez, M.B.; Portillo, A.U.; Cabada, R.Z.; Barrón, M.L. Impact of augmented reality technology on academic achievement and motivation of students from public and private Mexican schools. A case study in a middle-school geometry course. Comput. Educ. 2020, 145, 103734. [CrossRef]

45. Yilmaz, R.M.; Goktas, Y. Using augmented reality technology in storytelling activities: Examining elementary students' narrative skill and creativity. Virtual Real. 2017, 21, 75-89. [CrossRef]

46. Lin, P.-H.; Chen, S.-Y. Design and Evaluation of a Deep Learning Recommendation Based Augmented Reality System for Teaching Programming and Computational Thinking. IEEE Access 2020, 8, 45689-45699. [CrossRef]

47. Ok, M.W.; Haggerty, N.; Whaley, A. Effects of Video Modeling Using an Augmented Reality iPad Application on Phonics Performance of Students Who Struggle with Reading. Read. Writ. Q. 2021, 37, 101-116. [CrossRef]

48. Wen, Y. Augmented reality enhanced cognitive engagement: Designing classroom-based collaborative learning activities for young language learners. Educ. Technol. Res. Dev. 2021, 69, 843-860. [CrossRef]

49. Harley, J.M.; Lajoie, S.P.; Tressel, T.; Jarrell, A. Fostering positive emotions and history knowledge with location-based augmented reality and tour-guide prompts. Learn. Instr. 2020, 70, 101163. [CrossRef]

50. Steele, P.; Burleigh, C.; Kroposki, M.; Magabo, M.; Bailey, L. Ethical Considerations in Designing Virtual and Augmented Reality Products-Virtual and Augmented Reality Design with Students in Mind: Designers' Perceptions. J. Educ. Technol. Syst. 2020, 49, 219-238. [CrossRef]

51. Aggarwal, R.; Singhal, A. Augmented Reality and its effect on our life. In Proceedings of the 9th International Conference on Cloud Computing, Data Science \& Engineering (Confluence), Noida, India, 10-11 January 2019; pp. 510-515. [CrossRef]

52. Gray, C.M.; Boling, E. Inscribing ethics and values in designs for learning: A problematic. Educ. Technol. Res. Dev. 2016, 64, 969-1001. [CrossRef]

53. Heller, B. Watching Androids Dream of Electric Sheep: Immersive Technology, Biometric Psychography, and the Law. Vanderbilt J. Entertain. Technol. Law 2021, 23, 1-51. Available online: https://scholarship.law.vanderbilt.edu/jetlaw/vol23/iss1/1/ (accessed on 28 July 2021). 
54. Miller, M.R.; Herrera, F.; Jun, H.; Landay, J.A.; Bailenson, J.N. Personal identifiability of user tracking data during observation of 360-degree VR video. Sci. Rep. 2020, 10, 1-10. [CrossRef]

55. Bye, K.; Hosfelt, D.; Chase, S.; Miesnieks, M.; Beck, T. The ethical and privacy implications of mixed reality. In ACM SIGGRAPH 2019 Panels; ACM: New York, NY, USA, 2019; pp. 1-2. [CrossRef]

56. Gutiérrez, F.; Seipp, K.; Ochoa, X.; Chiluiza, K.; De Laet, T.; Verbert, K. LADA: A learning analytics dashboard for academic advising. Comp. Hum. Behav. 2020, 107, 105826. [CrossRef]

57. Zheng, R.Z.; Greenberg, K. Immersive Technology: Past, Present, and Future in Education. In Cognitive and Affective Perspectives on Immersive Technology in Education; IGI Global: Hershey, PA, USA, 2020; pp. 107-126.

58. Mangaroska, K.; Vesin, B.; Kostakos, V.; Brusilovsky, P.; Giannakos, M.N. Architecting Analytics Across Multiple E-Learning Systems to Enhance Learning Design. IEEE Trans. Learn. Technol. 2021, 14, 173-188. [CrossRef]

59. Boyles, B. Virtual Reality and Augmented Reality in Education; Center for Teaching Excellence, United States Military Academy: West Point, NY, USA, 2017.

60. Elmqaddem, N. Augmented Reality and Virtual Reality in Education. Myth or Reality? Int. J. Emerg. Technol. Learn. 2019, 14, 234-241. [CrossRef]

61. Klamma, R.; Ali, R.; Koren, I. Immersive Community Analytics for Wearable Enhanced Learning. In International Conference on Human-Computer Interaction; Springer: Cham, Switzerland, 2019; pp. 162-174.

62. Secretan, J.; Wild, F.; Guest, W. Learning Analytics in Augmented Reality: Blueprint for an AR/xAPI Framework. In Proceedings of the 2019 IEEE International Conference on Engineering, Technology and Education, Yogyakarta, Indonesia, 1-13 December 2019; pp. 1-6.

63. Kickmeier-Rust, M.D.; Albert, D. Learning analytics to support the use of virtual worlds in the classroom. In International Workshop on Human-Computer Interaction and Knowledge Discovery in Complex, Unstructured, Big Data; Springer: Berlin/Heidelberg, Germany, 2013; pp. 358-365.

64. Santamaría-Bonfil, G.; Ibáñez, M.B.; Pérez-Ramírez, M.; Arroyo-Figueroa, G.; Martínez-Álvarez, F. Learning analytics for student modeling in virtual reality training systems: Lineworkers case. Comput. Educ. 2020, 151, 103871. [CrossRef]

65. Marriott, K.; Schreiber, F.; Dwyer, T.; Klein, K.; Riche, N.H.; Itoh, T.; Thomas, B.H. (Eds.) Immersive Analytics; Springer: Berlin/Heidelberg, Germany, 2018; Volume 11190.

66. Dünser, A.; Billinghurst, M. Evaluating augmented reality systems. In Handbook of Augmented Reality; Springer: New York, NY, USA, 2011; pp. 289-307.

67. Saariluoma, P.; Cañas, J.J.; Leikas, J. Life-Based Design. In Designing for Life; Palgrave Macmillan: London, UK, 2016; pp. 171-206. [CrossRef]

68. Tzimas, D.; Demetriadis, S. Ethical issues in learning analytics: A review of the field. Educ. Technol. Res. Dev. 2021, 69, 1101-1133. [CrossRef]

69. Yuste, R.; Goering, S.; Arcas, B.A.Y.; Bi, G.-Q.; Carmena, J.M.; Carter, A.; Fins, J.J.; Friesen, P.; Gallant, J.; Huggins, J.E.; et al. Four ethical priorities for neurotechnologies and AI. Nat. Cell Biol. 2017, 551, 159-163. [CrossRef]

70. Applin, S.A.; Flick, C. Facebook's Project Aria indicates problems for responsible innovation when broadly deploying AR and other pervasive technology in the Commons. J. Responsible Technol. 2021, 5, 100010. [CrossRef]

71. Emadary, M.; Metzinger, T.K. Recommendations for Good Scientific Practice and the Consumers of VR-Technology. Front. Robot. AI 2016, 3, 3. [CrossRef]

72. Sahlberg, P. Finnish Lessons 3.0: What Can the World Learn from Educational Change in Finland? Teachers College Press, Columbia University: New York, NY, USA, 2021; ISBN 9780807779293. 